\title{
O CONCEITO ECOLÓGICO DO PATRIMÓNIO E A SUA VALORIZAÇÃO: O \\ CASO DA SERRA DE LEOMIL ${ }^{1}$
}

\author{
Ana Lopes ${ }^{2}$ \\ Emanuel de Castro ${ }^{3}$ \\ Ricardo Fernandes ${ }^{4}$
}

\section{RESUMO}

São os valores materiais ou imateriais, resultantes da interacção entre os grupos humanos e o espaço, e o próprio conceito ecológico da paisagem que nos conduzem à dicotomia que pretendemos apresentar neste artigo: a existência de Patrimónios fruto das diferentes interacções do Homem com o Meio, ou de um Património intrínseco aos diferentes Grupos Humanos, no entanto comum da Humanidade, que urge preservar pelas mais variadas razões.

Cada vez mais, o Património é visto como um factor de desenvolvimento e só desta forma se podem explicar as novas concepções de património, nomeadamente a Nova Museologia, directamente relacionada com o conceito ecológico do Património e consequentemente, neste caso, com os “modos de vida rurais”.

O presente artigo tem como objectivo aplicar esta discussão a uma área geográfica concreta, alvo de um estudo mais alargado e do qual apenas fazemos uma primeira abordagem metodológica; a Serra de Leomil.

\footnotetext{
${ }^{1}$ Com o apoio da Fundação para a Ciência e Tecnologia, através do projecto POCI/GEO/60243/2004

${ }^{2}$ Escola Superior de Educação do Instituto Politécnico da Guarda; anaventura@ipg.pt

${ }^{3}$ Escola Superior de Educação do Instituto Politécnico da Guarda; emanuelcastro@ipg.pt

${ }^{4}$ Licenciado em Geografia; ricardogeografia@mail.pt
} 


\section{ABSTRACT}

The material and immaterial values, resulting not only from the interaction between human groups and space, but also from the landscape ecological concept lead us to the dichotomy which we intend to present in this article: the existence of a heritage built from the diverse interaction between Man and Environment, or a heritage intrinsic to the various human groups, albeit stemming from humankind, which is urgent to protect due to numerous reasons.

Heritage is increasingly seen as a development factor and only thus can the new heritage concepts be explained, namely the New Museology, directly related to the heritage ecological concept and consequently, with the rural lifestyle.

This article has the objective of applying this issue to a specific geographical area, subject of a wider study and to which we are only executing a first methodological approach.

The Leomil Mountains, located between the Paiva and Távora rivers, are an example of the specific relationships occurring within the Human Groups and Space (acting as a home to their actions), incorporating different connections between the various landscape elements.

\section{RÉSUMÉ}

Ce sont les valeurs matérielles ou immatérielles, résultat de l'interaction entre les groupes humains et l'espace, et le concept écologique du paysage lui-même qui nous conduisent à la dichotomie que nous prétendons présenter dans cet article : l'existence de Patrimoines fruit des différentes interactions avec l'Environnement, ou d'un Patrimoine intrinsèque des différents Groupes Humains, cependant commun à l'Humanité, qu’il est urgent de préserver dû aux plus diverses raisons.

De plus en plus, le Patrimoine est vu comme un facteur de développement, c’est pourquoi il ne nous est possible d'expliquer les nouvelles conceptions de patrimoine que sous cette 
optique, notamment la Nouvelle Muséologie, directement liée au concept d’écologie du Patrimoine et, par conséquent, dans ce cas précis, liée aux “'modes de vie ruraux”.

Notre article présente comme objectif l'application de cette discussion à un espace géographique concret, cible d'une étude plus élargie et dont laquelle nous ne faisons qu'un premier abordage méthodologique : la montagne Serra de Leomil.

\section{NOTAS INTRODUTÓRIAS}

O mundo é o substrato e a cena em que se desenvolve o jogo da nossa aptidão. Ele é o palco sobre o qual os nossos conhecimentos são adquiridos e aplicados. Mas para que possa ser realizado o que o conhecimento dita como necessidade, é ainda necessário conhecer a constituição do sujeito, pois de outro modo o que acaba de ser dito é impossível. Para além disso, é também preciso aprender a conhecer a totalidade dos objectos da nossa experiência, afim de que os nossos conhecimentos não formem um agregado mas um sistema; porque num sistema o todo precede as partes, enquanto que, inversamente, num agregado são as partes que precedem o todo.

Neste sentido, o património surge-nos, inicialmente, relacionado com aspectos históricos e artísticos, contudo também se constitui num discurso sobre o passado cuja referência é um conjunto de valores arbitrados por determinados agentes sociais no sentido de legitimar determinados status vigentes.

São cartas mitológicas para toda a comunidade, destinando-se a definir essa comunidade. Mas esta definição deve incluir uma legitimação das suas estruturas de dominação política e económica através da qual a comunidade se identifique enquanto tal (FRENTRESS, et al., 1994). 
Tradicionalmente, tais expressões de património são apresentadas de forma dividida por subcategorias correspondentes às diferentes áreas do conhecimento científico. Desta forma, poderíamos falar em património cultural, natural, paisagístico, arqueológico e assim sucessivamente, enquanto expressões específicas supostamente dotadas de um autonomia capaz de insinuar a ausência de inter-relações.

Assim sendo, coloca-se a necessidade de estabelecer uma convergência destas subcategorias no sentido de enfatizar a formação do património enquanto um processo que terá como referência o ambiente no seu todo. À medida que a natureza transformada passa a fazer parte do habitat humano, também se submete a outras transformações pelo investimento de um novo trabalho, constituindo um processo de transformação sucessiva, materializada numa construção cultural.

Segundo DURHAM (1984) o património cultural deve ser concebido como cristalizações de um trabalho morto que se torna importante exactamente na medida em que se investe nele um novo trabalho cultural, através do qual o espaço adquire novos usos e novas significações. Uma das características deste processo de construção cultural reside exactamente no facto de que, quanto maior a carga simbólica conferida no passado a um bem cultural, tanto mais ricas serão as possibilidades da sua utilização futura.

Nesta perspectiva, temos assistido a um crescente e, cada vez mais, complexo número de iniciativas, a várias escalas, relacionadas com a valorização do património nas suas diferentes concepções, com o objectivo último de dotar espaços marginalizados de algum dinamismo económico e demográfico, na maioria dos casos directamente relacionadas com a actividade turística, assente no aproveitamento dos recursos endógenos. Nesta perspectiva, a Serra de Leomil, soerguida entre os rios Paiva e Távora, surge-nos como um exemplo da especificidade das inter-relações entre os Grupos Humanos e o Espaço, entendido como palco das suas acções, conjugando diferentes interligações entre os diversos elementos da paisagem. 
Assim, é imperativo percebermos até que ponto os elementos antropogénicos da paisagem e o seu substrato natural podem ser entendidos e valorizados patrimonialmente, contribuindo, desta forma, para o desenvolvimento local mais amplo que o mero aproveitamento turístico, cada vez mais necessário neste com em outros territórios.

\section{O CONCEITO DE PATRIMÓNIO E A SUA EVOLUÇÃO}

Segundo a sua acepção clássica, o conceito de património refere-se ao legado que herdamos do passado e que transmitimos a gerações futuras. Ainda que esta definição não tenha perdido validade, não podemos entender o património apenas como os vestígios tangíveis do processo histórico. Todos os processos antrópicos têm uma existência física territorial e num determinado período, que através da própria dinâmica da existência, estes objectos do passado alimentam, pela sua permanência no tempo, a criatividade de novas gerações de produtores de objectos, que acrescentam elementos às gerações anteriores. A estruturação do conceito de património afirma-se, então, como a base de qualquer análise de processos de construção e destruição de um património. O que significa que a palavra mais do que se converter num acto ou num objecto, converte-se em representação de alguma coisa (PEIXOTO, 2002)

Neste sentido o conceito surge quando um individuo ou um grupo de indivíduos identifica como seus um objecto ou um conjunto de objectos materiais ou imateriais, transcritos num espaço que identificam como seu (BALLART, 1997).

Tal noção de património com a ideia de possa que lhe está implícita, sugere-nos imediatamente que estamos na presença de algo de valor, valor este que durante muito tempo se pautou por princípios claramente materiais. Desta forma, a primeira vez que em Portugal se evoca o dever de salvaguarda de património, foi no reinado de D. João V, 1721, onde eco património era remetido a "edifícios, mármores, estátuas...." que não se deviam perder uma vez, que este dano poderia ser prejudicial à glória da nação portuguesa, desejando El-Rei 
desta forma "contribuir para impedir um prejuízo tão sensível e tão danoso à reputação e glória da antiga Lusitânia”. Estando, assim “as câmaras das cidades e das vilas deste reino, obrigadas a particular cuidado em conservar e guardar todas as antiguidades sobreditas e a semelhante qualidade que as conserva”.

Contudo, este conceito é subjectivo uma vez que varia com as pessoas e com os grupos humanos que lhe atribuem esse valor, permeável às flutuações da moda e aos critérios dos gostos dominantes, materializados pelo figurino intelectual, cultural e psicológico de uma determinada época e de um determinado lugar.

Segundo PRATS (1997), o património é uma construção social, um processo de legitimação social e cultural. Falar em património pressupõe falar em identidades, na medida em que pode ser definido como uma síntese simbólica de valores identitários que contribuem para um sentido de pertença e de identificação de um colectivo social.

Apenas nesta perspectiva podemos entender a corrente da Nova Museologia, surgida com a Carta de Santiago em 1972 e mais tarde em 1984, com a Declaração de Quebec, em que se evoca cada vez mais a participação da comunidade nos museus, incentivando o movimento dos ecomuseus, em que o palco deixa de ser um edifício fechado e estanque para ser o território, onde paralelamente se preservam identidades locais e onde se mantém continuamente uma relação harmoniosa das acções humanas, protegendo pontualmente alguns aspectos significativos da fauna e da flora e tentando manter vivas as actividades tradicionais da população, que estão na origem da paisagem, resultado das inter-relações Homem-Meio. A paisagem tem vindo a adquirir, ao longo dos anos, um carácter cada vez mais social e menos natural, palco privilegiado das novas concepções de património. 


\section{O CONCEITO ECOLÓGICO DO PATRIMÓNIO E A SUA VALORIZAÇÃO ENQUANTO RECURSO SUSTENTÁVEL}

Na sequência da linha de análise podemos falar no conceito ecológico do património, uma vez que as condições de vida dos Grupos Humanos estão estreitamente ligadas ao meio ambiente, nos seus mais abrangentes aspectos físicos e biológicos. Isto é, as condições de vida humanas são, fortemente, condicionadas pelos factores ecológicos e ambientais, resultando em diferentes formas de adaptação do Homem aos condicionalismos impostos. Sendo assim, qualquer património só é adjectivado, como tal, devido à valorização feita pelos grupos humanos que, no fundo, ou dele dependem ou o criaram.

Devido à complexidade da definição do conceito de Património e da ambiguidade do mesmo, optámos por nos remeter à definição da Organização das Nações Unidas, apresentada na Convenção sobre a Protecção do Património Mundial Cultural e Natural, aprovada pela UNESCO em 1972. "Por Património Cultural entende-se monumentos, grupos de edifícios e sítios que tenham valor histórico, estético, arqueológico, científico, etnológico ou antropológico. Património Natural são formações físicas, biológicas ou geológicas consideradas excepcionais, habitats animais e vegetais ameaçados, e áreas que tenham valor científico, de conservação ou estético”.

O Património Cultural e o Património Natural estão cada vez mais ameaçados, não só pelas causas tradicionais de degradação, mas também pela evolução da vida social e económica que as agrava através de fenómenos de alteração e de destruição ainda mais temíveis (Convenção da UNESCO, Preâmbulo). 


\section{A SERRA DE LEOMIL ENQUANTO ELEMENTO GEOGRÁGICO DE}

\section{IDENTIDADE}

\subsection{Localização e contextualização da área de estudo}

A Serra de Leomil, soerguida entre os rios Paiva e Távora, surge-nos como um exemplo da especificidade das inter-relações entre os Grupos Humanos e o Espaço, entendido como palco das suas acções, conjugando diferentes inter-relações entre os diversos elementos da paisagem. A área de estudo do presente artigo enquadra-se espacialmente no concelho de Moimenta da Beira e, consequentemente, na sub-região do Douro, integrando algumas freguesias do concelho supracitado (Figura 1).

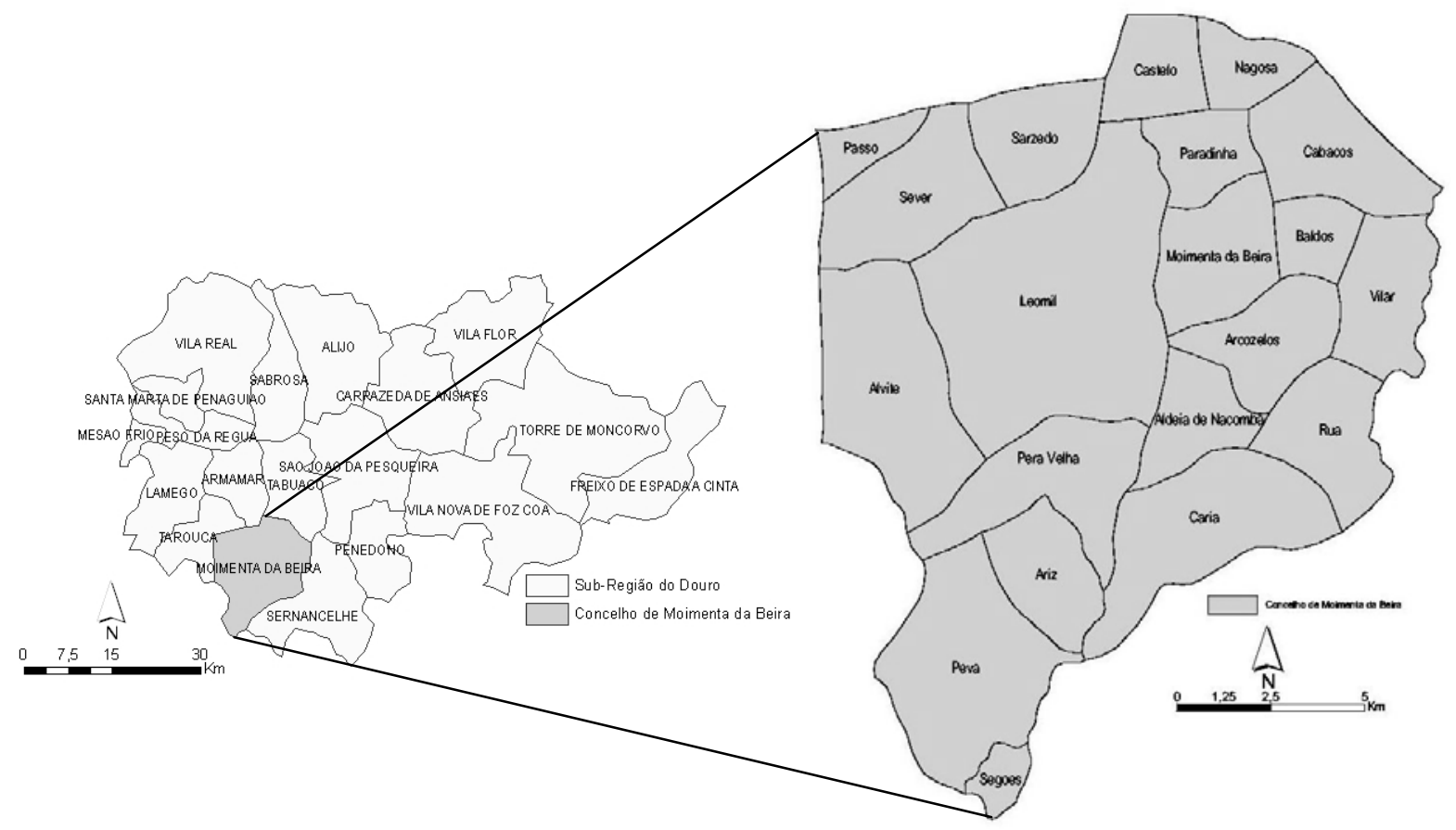

Figura 1. Localização do Concelho de Moimenta da Beira

Este território insere-se, morfologicamente, num grupo de unidades de paisagem que, por sua vez formam "um vasto plano inclinado drenado, quase todo, pelos sistemas do Mondego e Douro” (RIBEIRO, 1993). Para além destas redes hidrográficas, o Rio Vouga contribui para a modelação de outras serras, como a de Montemuro e Leomil, bem como outras áreas de 
características mais ou menos onduladas e de vales igualmente expressivos. Se em alguns aspectos existe homogeneidade, não podemos deixar de referir que a área "comporta” uma paisagem de contrastes. A Serra de Leomil é, no seu todo, um reflexo dos sistemas montanhosos da Beira Alta. Aos elevados blocos rochosos, aos cumes áridos, desertificados e despovoados, opõem-se, num mesmo território, as zonas mais baixas, as encostas e vales agrícolas, onde o clima, a hidrologia e o tipo de solos atenuam a agressividade da paisagem.

No século XVIII denominava-se Serra da Nave, facto confirmado por alguns registos da época, nomeadamente os inquéritos e memórias paroquiais. “A Serra a meyas fraldas está a Villa de Leomil chamada Nave” (Memórias Paroquiais), que se ergue entre os rios Távora e Paiva e pertence ao Maciço Galaico-Duriense. A intitulada Serra da Nave situa-se entre Alvite, Almofala, Touro, Ariz, Pêra Velha, Carapito e Leomil, sendo muito importante, ao longo dos tempos, para esta última freguesia, realidade que lhe deu o nome que hoje conhecemos.

Actualmente, nos mapas, cartas militares e outras publicações, aparece como Serra de Leomil, fruto da ligação da população "leomilense” à serra que brota diante dos seus olhos. Leomil, no sopé da serra, teve sempre uma forte relação com esta a nível socio-económico, sendo que a conotação de nave proveio como alusão ao planalto existente no seu topo. Lobgueira, Nave ou Leomil, foram os diferentes nomes que teve ao longo dos tempos. Porém, o interesse que nos desperta vai para além desta toponímia, procurando as dinâmicas socio-económicas, a relação das populações com o seu território e a sua valorização patrimonial, sem com isto entrar em processos de patrimonização desmedidos.

Todo o território apresenta características montanhosas, com altitudes que atingem cotas de 1011 metros, sendo o principal conjunto constituído pela Serra de Leomil na área sudoeste do Concelho de Moimenta (Figura 2). As cotas entre os 950 e os 1011 metros de altitude, aproximadamente, apresentam um carácter aplanado, integrando uma importante unidade de 
planaltos, constituída pelo Planalto da Nave que corresponde a um aplanamento inclinado para sudoeste. Leomil, no sopé da montanha, encontra-se implantada numa área granítica de transição, adjacente a outras freguesias, como Alvite, Pêra Velha, Sarzedo, Castelo, Moimenta da Beira e Aldeia de Nacomba.

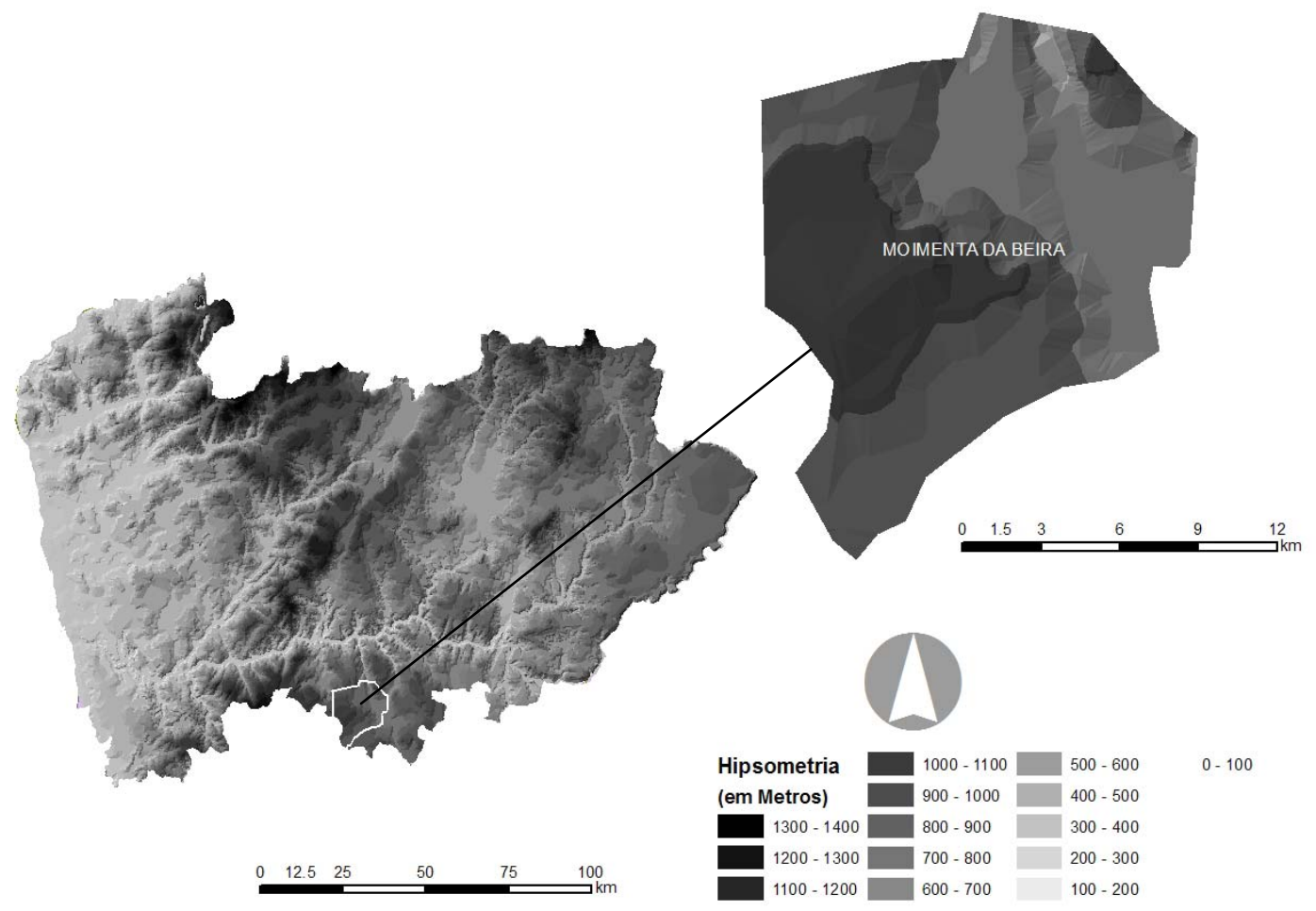

Figura 2. Enquadramento da Serra de Leomil

Na generalidade, os traços dominantes na Serra de Leomil são de natureza ténue, porém de características demarcadamente montanhosas. A par da Serra da Lapa, constitui um sistema com uma elevação de altitude significativa, embora sem formas muito vigorosas e cortes abruptos, mas de traços arredondados e imponentes, característico dos relevos graníticos antigos (DGOTDU, 2005). Nas zonas de maior altitude, tanto as mais acidentadas, como as mais comuns, as planálticas, são dominantes as sensações de profundidade, a que se associa a agressividade e aridez, com a existência de rochas que se encontram praticamente nuas e a um coberto vegetal rasteiro. Nas zonas mais baixas, a aridez transforma-se, lentamente, com base 
na convivência entre as linhas de água, solos mais produtivos e uma maior biodiversidade, factores que poderão justificar uma maior apetência agrícola e a localização de algumas das maiores povoações da área, como é o caso da Vila de Leomil.

Apesar da existência de condições estruturantes que podem dificultar a actividade humana, as populações da serra souberam, desde sempre, aproveitar a força da água. Os terrenos adjacentes às diferentes linhas de água apresentam-se em situação de várzea, contendo solos consideravelmente mais ricos e de grande importância nos aluviosolos, cuja aptidão agrícola é superior, relação que podemos constatar pelo construído ao longo da serra. Este condicionalismo reflecte-se, não só nas relações com o meio físico, mas também nos próprios factores climáticos. Tal como se verifica noutras serras, como Montemuro e Lapa, o clima da Serra de Leomil apresenta características significativamente diferentes das regiões em que se inserem, sendo, segundo Orlando Ribeiro (1988) áreas marcadas por uma forte dissimetria climática. As partes mais elevadas apresentam ritmos climáticos afins dos registados nos diversos sopés, com cambiante em geral mais atlântica, enquanto os vales mais profundos e abrigados podem exacerbar os aspectos continentais, próprios da região onde se situam (RIBEIRO, O. et al., 1988).

\subsection{Caracterização Demográfica e Socio-Económica}

A especificidade da área de estudo não depende apenas dos aspectos do meio, isto é, do elemento físico da paisagem natural e dos seus condicionalismos. O Homem e a sua acção têm um papel decisivo nas características do território, tornando-se imprescindível uma breve abordagem demográfica e socio-económica, tentando compreender os aspectos relevantes ao nível antrópico e das relações entre o meio e os grupos humanos que o ocupam.

Como já referimos, o concelho de Moimenta da Beira abrange, praticamente, a quase totalidade do Planalto da Nave, da referida serra. Nesta perspectiva, torna-se imperativo, 
perante os objectivos a que nos propomos, fazer uma breve caracterização por freguesias, sublinhando as mutações demográficas e socio-económicas das diferentes unidades, tendo em atenção a sua relação com a orografia da serra.

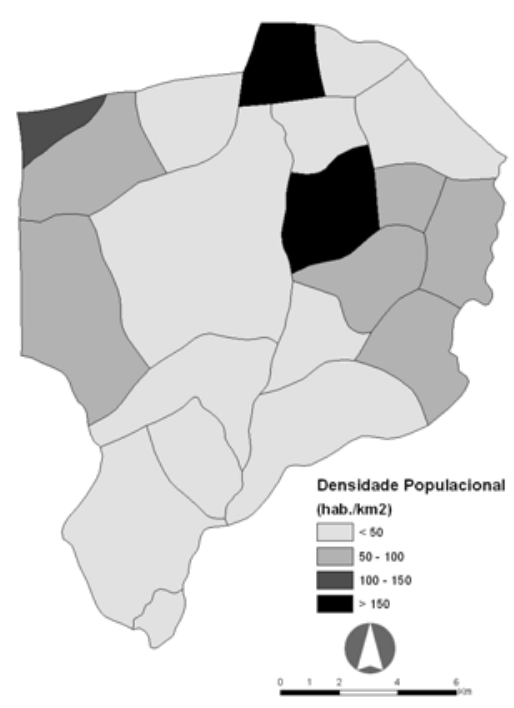

Figura 3. Densidade Populacional no Concelho de Moimenta da Beira em 2001

Fonte: Censos 2001

Numa primeira escala, a Densidade Populacional do concelho é de 49,9 habitantes por $\mathrm{Km}^{2}$, porém, esta é uma realidade que pode esconder uma forte heterogeneidade quando analisada a uma maior desagregação, como é o caso das freguesias. Assim, as maiores densidades registam-se nas freguesias de características urbanas, como Moimenta da Beira e Castelo, com 259,22 e 315 habitantes por $\mathrm{Km}^{2}$, respectivamente.

Nas freguesias caracterizadas pelo elemento geográfico da serra, como Leomil, Alvite e Pêra Velha, as densidades populacionais são menores, fruto não só da especificidade física do espaço, mas também de uma ruralidade cada vez mais retalhada e envelhecida (Figura 3). Este envelhecimento, predominante nas freguesias com maior ruralidade e de maiores altitudes, reflecte o baixo poder de atractividade deste espaço, caracterizado por um forte êxodo 
populacional nas últimas décadas, principalmente nas freguesias de Alvite e Pêra Velha, coincidentes com os maiores valores de altitude (Planalto da Nave) (Figura 4).

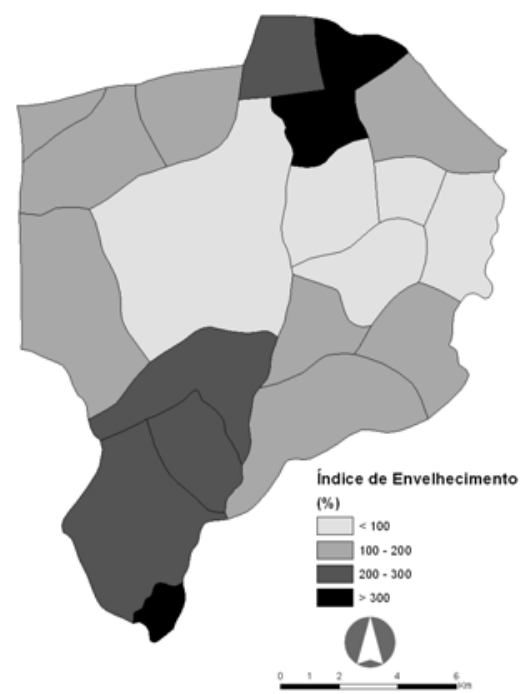

Figura 4. Índice de Envelhecimento no Concelho de Moimenta da Beira em 2001

Fonte: Censos 2001

Contudo, o índice de envelhecimento observado nas freguesias de Leomil e Moimenta da Beira apresentam valores reduzidos, relacionados com índices de urbanização mais elevados, resultando em espaço mais atractivos para a fixação populacional.

Esta realidade reflecte-se nas mutações demográficas registadas ao longo de um período de tempo. Atendendo à variação da população no período inter-censitário, 1991 a 2001, constatamos que grande parte do concelho registou uma perda de população, em algumas freguesias, superior a 20 por cento. As únicas freguesias que apresentam aumentos populacionais, embora pouco significativos, são Leomil e Moimenta da Beira, fruto de um maior poder atractivo e índices fisiológicos superiores às restantes freguesias do concelho, realidade a que não é alheia a influência da “urbanidade” verificada na sede do mesmo (Figura 5). 


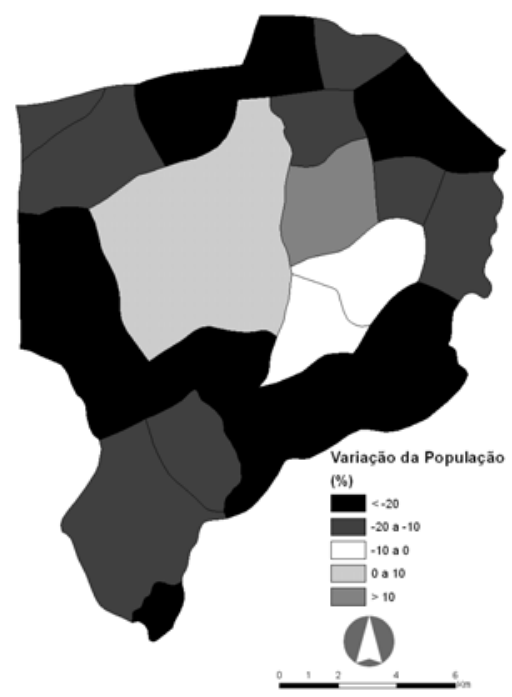

Figura 5. Variação da População no Concelho de Moimenta da Beira entre 1991e 2001

Fonte: Censos 1991/2001

Apesar da importância dos indicadores de ordem demográfica para a caracterização de um território, com as características do presente, em que a ruralidade e o factor montanha são bastante representativos nas dinâmicas populacionais, não podemos dissociá-lo dos comportamentos socio-económicos, que podem ser encarados como causa e efeito dos “modos de vida territoriais". 
Quadro I. População por Sector de Actividade no Concelho de Moimenta, em 2001

\begin{tabular}{|c|c|c|c|c|c|}
\hline & \multicolumn{4}{|c|}{ População Empregada por sector de actividade } & \multirow{2}{*}{$\begin{array}{c}\text { Taxa de } \\
\text { Desemprego }\end{array}$} \\
\hline & Sec. Primário & Sec. Secundário & Sec. Terciário & Total & \\
\hline Castelo & 37,6 & 29,7 & 24,75 & 92,1 & 7,92 \\
\hline Nagosa & 10,3 & 0,0 & 58,62 & 69,0 & 31,03 \\
\hline Cabaços & 15,1 & 32,8 & 44,54 & 92,4 & 7,56 \\
\hline Sarzedo & 47,2 & 15,3 & 20,83 & 83,3 & 16,67 \\
\hline Sever & 14,6 & 16,7 & 42,06 & 73,4 & 26,61 \\
\hline Passô & 27,9 & 36,9 & 29,51 & 94,3 & 5,74 \\
\hline Paradinha & 29,7 & 10,8 & 40,54 & 81,1 & 18,92 \\
\hline Leomil & 23,4 & 21,7 & 45,82 & 90,9 & 9,07 \\
\hline Moimenta da Beira & 5,2 & 16,5 & 68,79 & 90,6 & 9,44 \\
\hline Baldos & 2,6 & 33,3 & 38,46 & 74,4 & 25,64 \\
\hline Vilar & 12,4 & 24,2 & 40,72 & 77,3 & 22,68 \\
\hline Alvite & 36,2 & 12,5 & 48,41 & 97,1 & 2,93 \\
\hline Arcozelos & 4,4 & 14,9 & 57,26 & 76,6 & 23,39 \\
\hline Aldeia de Nacomba & 26,7 & 24,4 & 35,56 & 86,7 & 13,33 \\
\hline Rua & 4,7 & 27,9 & 56,98 & 89,5 & 10,47 \\
\hline Pêra Velha & 57,0 & 12,9 & 25,81 & 95,7 & 4,30 \\
\hline Caria & 29,2 & 26,3 & 40,35 & 95,9 & 4,09 \\
\hline Ariz & 19,0 & 18,0 & 63,00 & 100,0 & 0,00 \\
\hline Peva & 36,2 & 12,3 & 34,06 & 82,6 & 17,39 \\
\hline Segões & 38,5 & 15,4 & 30,77 & 84,6 & 15,38 \\
\hline
\end{tabular}

Fonte: Censos 1991/2001

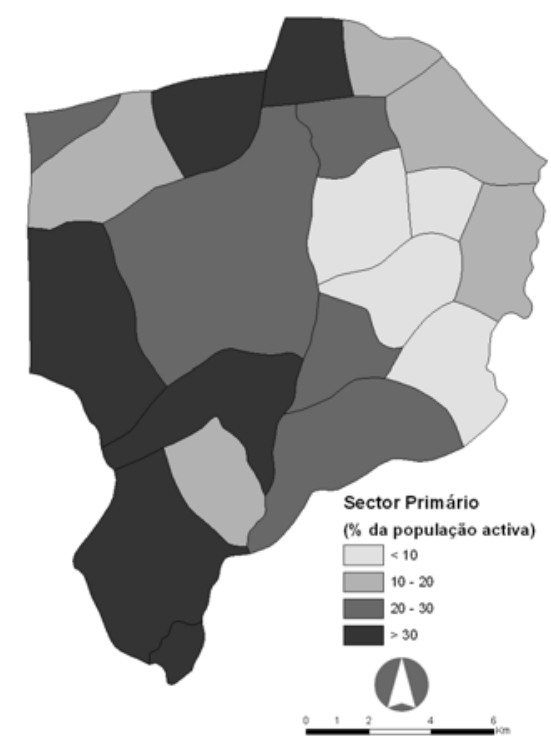

Figura 6. População no Sector Primário no Concelho de Moimenta da Beira em 2001

Fonte: Censos 2001

Desta forma, parece-nos pertinente estudar a estrutura económica da população. Assim, em relação a percentagem de população empregada por sector de actividade, torna-se importante observar o comportamento espacial da população nos diferentes sectores de actividade (Quadro 1). Na maior parte das freguesias a predominância vai para maiores percentagens da população empregada no sector terciário, contudo, Castelo, Segões, Peva, Sarzedo e Pêra Velha, vêm no sector primário a maior parte da usa população empregada, sendo que as duas últimas abrangem o planalto da Serra de Leomil (Figura 6). Com valores reduzidos de população no sector primário, encontramos as freguesias de Rua, Moimenta da Beira, Baldos e Arcozelos, com 4,7 por cento, 5,2 por cento, 2,6 por cento e 4,4 por cento, respectivamente, sendo as últimas três de carácter mais urbano, justificando, desta forma, uma maior terciarização da sua economia. 
Como referimos, são as freguesias mais urbanas que apresentam valores de população no sector terciário mais elevados. Contudo, ao analisarmos estas percentagens surgem-nos aspecto que questionam as dinâmicas socio-económicas de algumas freguesias. Por exemplo, atendendo aos casos de Nagosa e Paradinha, duas freguesias com menores dinâmicas demográficas, com índices de envelhecimento elevados, com as menores densidades populacionais e um decréscimo acentuado da população, torna-se interessante depararmo-nos com valores percentuais de população empregada no sector terciário na ordem dos 58.6 por cento e 40.5 por cento, respectivamente. Este cenário só poderá ser explicado se encaramos a sua população activa como uma população pendular que se desloca para a sede do concelho ou para o seu exterior. Atendendo a outros indicadores de índole social, a Taxa de Analfabetismo assume um papel relevante na condição social da população residente neste espaço (Figura 7).

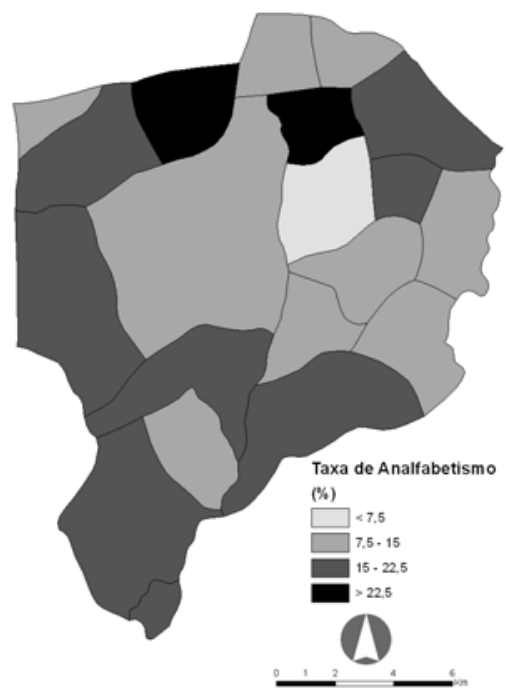

Figura 7. Taxa de Analfabetismo no Concelho de Moimenta da Beira em 2001

Fonte: Censos 2001

O valor mais baixo, 6.2 por cento é referente à sede de concelho, porém, este número desfasa totalmente da realidade vivida no resto do concelho, onde observamos taxas bastante mais 
elevadas. Neste campo, existe um reforço negativo das freguesias marcadas pelo planalto da Serra de Leomil, o que pode indicar que, para além do PIB per capita, os aspectos de ruralidade e o factor montanha podem estar na origem das causas deste cenário. Um outro aspecto pode ser de âmbito mais sociológico, isto é, ligado aos modos de vida destas populações, que desde sempre se encontraram ligadas à actividade agro-pastoril. Este cenário vem corroborar os aspectos já referidos e a especificidade deste espaço e as relações entre os grupos humanos e o meio, fortemente marcadas pelo despovoamento e pela agricultura de subsistência.

\section{AS MARCAS ANTRÓPICAS NO ESPAÇO COMO RECURSO A VALORIZAR PATRIMONIALMENTE}

Na unidade espacial, definida como área de estudo, a Serra de Leomil, verifica-se uma generalizada coerência dos usos territoriais que, de certa forma, se encontram assentes numa forte interligação entre o Homem e o Meio. O Homem, entendido como os Grupos Humanos e, o Meio, o território e espaço suporte e produto, físico, social, cultural, resultado das acções dos primeiros em relação ao último e do condicionamento que se verifica na relação inversa. Podemos, então, por um lado, encarar o Homem como modelador do Meio e criador de novos territórios, mas, por outro, aceitar o Meio como forte condicionador das actividades humanas e limitador da liberdade humana perante os seus limites físicos de actuação. Da panóplia de sub-relações existentes entre esses dois agentes globais, criam-se condições de especificidade que, na área determinada, assumem características singulares.

A especificidade dos lugares, das pessoas e das suas percepções provêm de inúmeras fracções que se prendem com factores naturais e antrópicos. Partindo do pressuposto que, a maior parte dos lugares e dos territórios são, em si mesmo, específicos e singulares, torna-se difícil separar, metodologicamente as suas importâncias. Todavia, na nossa perspectiva, o espaço 
rural, marcado pela morfologia montanhosa, acarreta conceptualmente ligações únicas e de difícil interpretação, tanto ao nível das dinâmicas demográficas, económicas e sociais, bem como no que se refere ao(s) património(s) entendidos enquanto marcas antrópicas no espaço, a paisagem e os próprios modos de vida. Como referimos anteriormente, no que concerne ao uso do espaço, temos que ter em conta as suas características biofísicas, humanas, mas também, a acção antrópica, a sua génese e características, pois, só desta forma, poderemos cruzar diferentes usos territoriais, diagnosticá-los e tentar manter um equilíbrio ecológico e funcional entre a presença humana e a sua valorização patrimonial.

Interessa-nos, assim, tratar a paisagem como expressão dos componentes ecológicos em permanente evolução e do reflexo da actividade de gerações com os seus valores culturais sobre o território. A “antropização” da paisagem incute no território características singulares, resultantes da própria intervenção do Homem no Meio, sendo o ordenamento do território o processo que visa a organização dos usos.

Indo ao encontro daquilo que são as premissas fundamentais da Nova Museologia, como sendo os grupos humanos e o território, numa tentativa de dotar estes espaços demográfica e economicamente deprimidos de algum dinamismo, urge criar, tendo em conta as potencialidades do espaço, políticas de desenvolvimento integradas vocacionadas para as singularidades territoriais, em que a forma de actuação deverá estar particularmente sensível às necessidades e anseios sociais da população autóctone.

No fundo, valorizar a relação dos indivíduos com o espaço e das comunidades com o seu património, como elos de integração social, tendo em conta os seus discursos e linguagens, os diferentes códigos culturais, permitindo o seu reconhecimento e valorização (Declaração de Caracas, 1992). Esta valorização social do património conduziu a um crescente número de políticas cujo principal objectivo seria desenvolver um conjunto de acções no sentido de 
resgate e activação do património cultural protagonizado pelos agentes locais e pelos próprios poderes institucionais.

Quando estamos em presença de territórios, cujas potencialidades naturais aliadas ao património construído, passíveis de se tornarem destinos turísticos de qualidade é, estrategicamente, mais viável a implementação de políticas ligadas ao turismo. No caso presente, em que não podemos falar em zona turística, o património relaciona-se com finalidades simbólicas, identitárias e de melhoria da qualidade de vida da população local, sendo que neste caso é complicado efectuar uma implementação e, consequente, avaliação dos resultados alcançados pelos projectos turístico-patrimoniais.

No seguimento daquilo que temos afirmado, o Planalto da Nave apresenta-se disseminado por pequenos nichos populacionais com uma clara perda de dinamismo populacional e socioeconómico. A par desta perda assiste-se, igualmente, a um abandono dos modos de vida e consumos de espaço tradicionais, que caracterizam este território e que lhe incutem uma referência de identidade.

Desta forma, torna-se urgente inverter este cenário sob pena de, a curto prazo, assistirmos a processos de despovoamento irreversíveis com consequências ao nível da desertificação física do solo e da degradação daquilo que são as marcas que o Homem foi construindo no espaço e que revelam uma cultura de comportamento. Neste sentido a valorização endógena e exógena é fundamental, como um princípio e não um fim em si mesmo, na tentativa de contrariar esta realidade cada vez mais próxima.

\section{VALORIZAÇÃO DOS RECURSOS PARA O DESENVOLVIMENTO LOCAL}

Em territórios com especificidades peculiares, como é o caso do presente, urge seguir uma política assente na valorização dos recursos endógenos contribuindo, desta forma, para o desenvolvimento local. Nesta perspectiva, torna-se necessário mudar a escala de análise, 
passando a estudar o Planalto da Nave que integra parte das freguesias de Alvite, Leomil e Pêra Velha (figura 8).

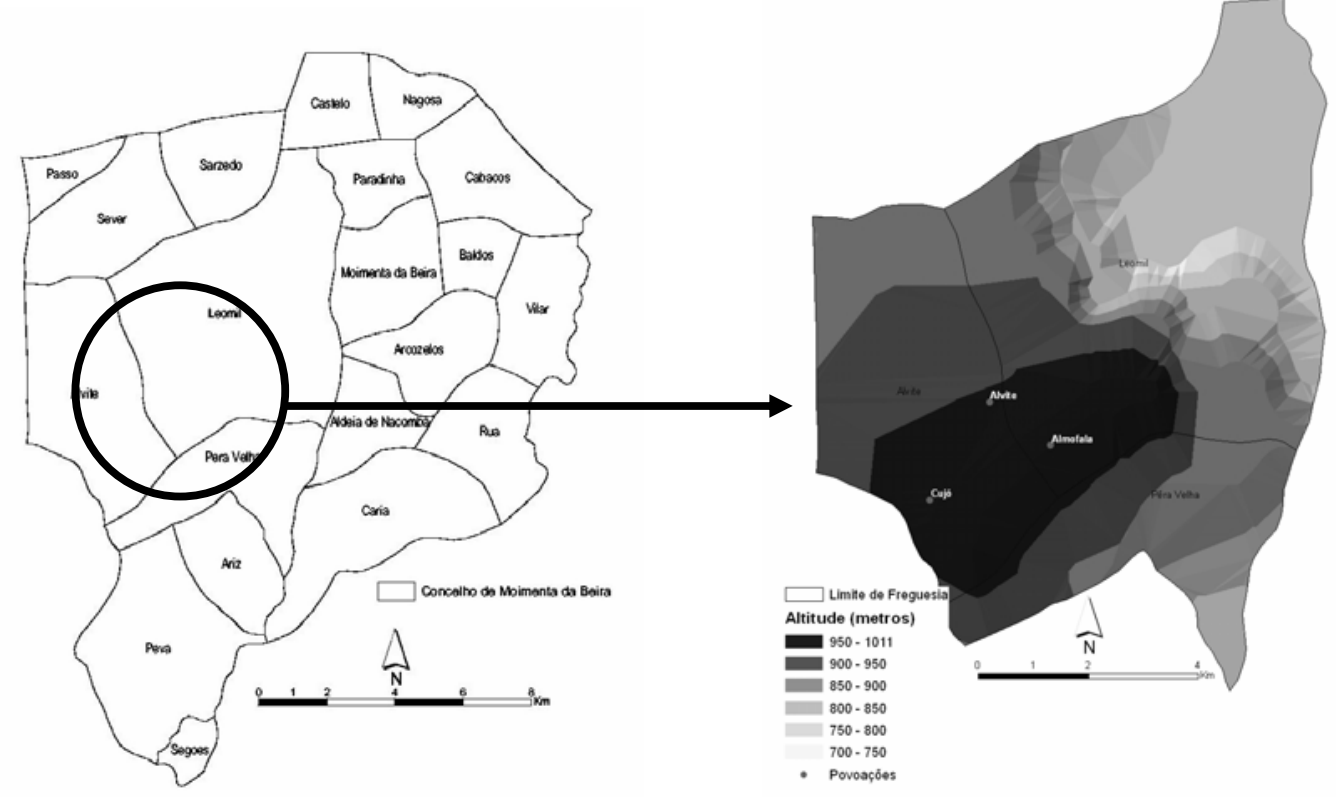

Figura 8. Identificação da área de estudo

Assim, tendo em conta as características do território, escolhemos três exemplos práticos, Alvite, Cujo e Almofala (figura 9), cuja valorização dos recursos endógenos e exógenos deverá contribuir para a recuperação da identidade deste espaço. Só desta forma se poderá inverter, a médio prazo, o cenário de despovoamento humano, com as consequentes alterações físicas ao nível do solo e da própria paisagem. 


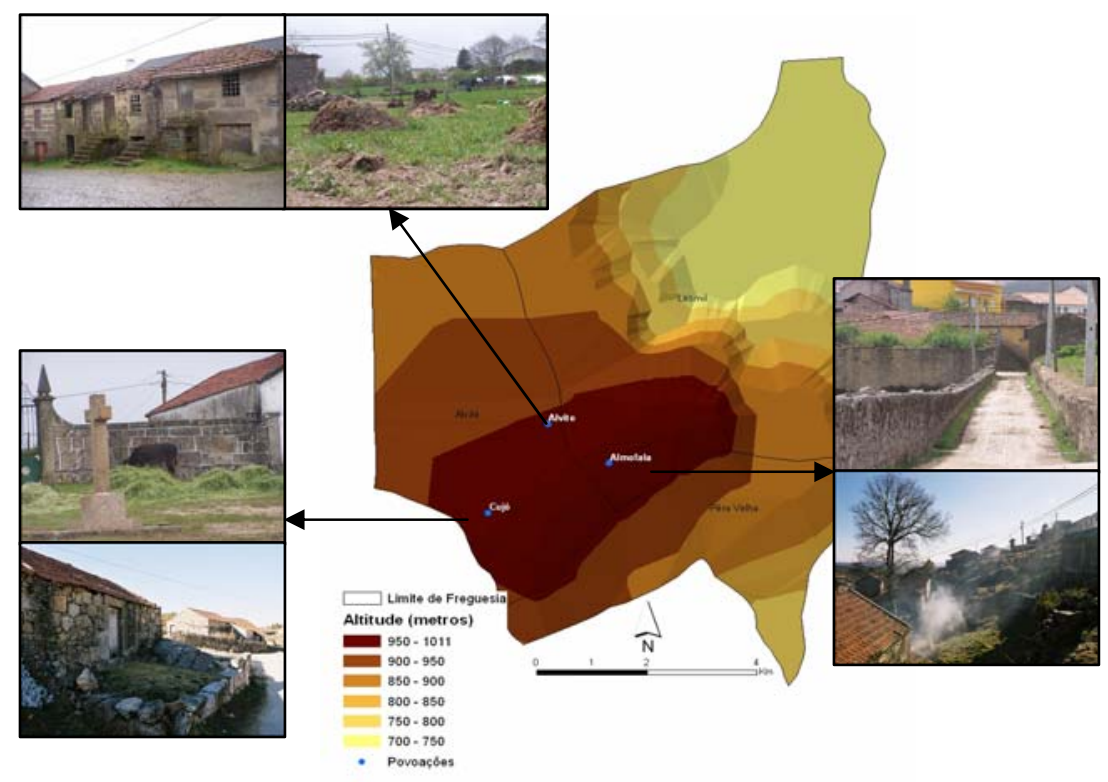

Figura 9. Três exemplos da especificidade territorial

A classificação patrimonial do território, atendendo às marcas resultantes da acção do Homem na paisagem, deverá ser cada vez mais valorizada, pois só a partir dela podemos retirar conclusões acerca daquilo que é uma cultura de comportamento. Neste contexto, o património no Planalto da Nave, como em outros territórios, deverá ser entendido como um legado intrínseco aos grupos humanos que no fundo, ou dele dependem, ou o criaram. Torna-se necessário, antes de mais, que a valorização seja feita ao nível das populações para que estas possam valorizar um território e as marcas que nele foram sulcando. Só desta forma, podemos contribuir para a valorização daquilo que consideramos como um recurso concorrendo para um desenvolvimento integrado.

\section{NOTAS CONCLUSIVAS}

O Património deve ser entendido como um legado intrínseco dos povos e das gentes que lhes adstringem valor. Estes lugares são vazios e descontextualizados, são representações plásticas de um passado irreal. Desta forma, não é correcto considerarmos o Património característico 
de um determinado modo de vida como um recuso turístico per si. Uma vez que a maior parte das vezes a actividade turística entendida como actividade económica que na realidade é, não vai de encontro às reais necessidades das populações autóctones, sendo tomadas decisões que podem ir em alguns casos contra as próprias características da população, alterando o seu quotidiano e consequentemente os seus modos de vida tradicionais que as tornam particulares e diferentes de todas as outras culturas.

A cultura, o passado e o património não se vendem nem se compram e se venderem ou comprarem todo o sentido último subjacente à expressão cultural dos povos será expropriado. Ao invés da actividade turística se figurar como um instrumento de conservação ambiental e criação de benefícios socio-económicos para as comunidades receptoras, esta acaba, em geral, por aumentar o processo de degradação ambiental, gerando desequilíbrios socio-económicos e desvalorização cultural.

Toda e qualquer intervenção patrimonial deve ser desenvolvida a uma escala local, promovendo a participação activa de todos os agentes, uma vez que para se alcançar o verdadeiro desenvolvimento torna-se necessário uma participação articulada e descentralizada, muito mais ampla que a mera representação patrimonial.

Torna-se condição primordial a realização de estudos de impacte e viabilidade que permitam sustentar a relação directa entre património e desenvolvimento, tendo sempre em atenção as reais necessidades das populações autóctones e sem sobrecarregar o espaço, tentando desta forma, definir e tornar exequíveis determinados objectivos que tendem ao desenvolvimento local.

\section{BIBLIOGRAFIA:}

ANDRIEUX, Jean-Yves (1997) - Patrimoine et Histoire. Belin, Paris.

BABELON, Jean-Pierre (2000) - La notion de patrimoine . Collection Opinion, Paris. 
BALLART HÉRNANDEZ, Josep (2001) - Gestion del Património Cultural. Ariel, Barcelona BÉGHAIN, Patrice (1998) - Le patrimoine: culture et lien social. Presses de Sciences, Paris. FRENTRESS, J. ; WICKHMAN, C. (1994) - Memória Social. Teorema, Lisboa DGOTDU (2005) - Contributos para a Identificação e Caracterização da Paisagem em Portugal Continental. Edição Estudos 10, Universidade de Évora, Lisboa.

DURHAM, E. (1984) - Cultura, Património e Preservação. Brasiliense, São Paulo HOWARD, Peter (2003) - Heritage: Management, Interpretation, Identity. Continuum, London.

GREFFE, Xavier (1999) - La Gestion du Patrimoine Culturel. Anthropos, Paris.

LEIMGRUBER, Walter (2003) - “A Paisagem Humanizada Face aos Valores Humanos”. Território, Ambiente e Trajectórias de Desenvolvimento, IV, Coimbtra, pp. 23-34

PEIXOTO, Paulo (2002) - “Os Meios Rurais e a Descoberta do Património”; Oficina do CES, 175, Coimbra.

PRATS, L. (1997) - Antropologia y Património. Editorial Ariel, Barcelona.

REIS, José (2001) - “Observar a Mudança: o papel dos estudos rurais”. Oficina do CES, 165, Coimbra.

RIBEIRO, Orlando et al. (1998) - Geografia de Portugal. Segundo Volume, Edições João Sá da Costa, $4^{\mathrm{a}}$ Edição. Lisboa. 